\title{
Potentiality assessment of fish scale biodegradation using mangrove fungi isolated from Indian Sundarban
}

\author{
Vaswati Nandy ${ }^{1}$, Madhurima Bakshi ${ }^{1}$, Somdeep Ghosh ${ }^{1}$, Harish Sharma ${ }^{1}$, \\ Barnali Ray Basu' ${ }^{2}$, Punarbasu Chaudhuri ${ }^{1, *}$ \\ ${ }^{1}$ Department of Environmental Science, University of Calcutta, 51/2 Hazra Road, \\ Kolkata - 700019, India \\ ${ }^{2}$ Department of Physiology, Surendranath College, 24/2 Mahatma Gandhi Road, \\ Kolkata - 700009, India \\ *E-mail address: punarbasu_c@yahoo.com
}

\begin{abstract}
The mangrove fungi, morphologically and physiologically adapted in a different habitat, were isolated from mangrove habitat of Jharkhali, Sundarban, India. The physico-chemical properties like temperature, $\mathrm{pH}$, soil colour, moisture content, carbon and nitrogen content of soil determines the load of microbial population. The soil sample was serially diluted and plated on potato dextrose agar plate with ampicillin to obtain fungal isolates. Total of six isolates were characterized microscopically by lacto phenol cotton blue staining. Two of them were identified as Aspergillus niger and Penicillium sp. and are subjected to biodegradation of fish scale, the major waste of fish processing industries. Aspergillus niger was found to be the best for degradation of fish scale powder by producing zone of clearance. Moreover, media without fish scale didn't show any zone of clearance indicates the mangrove fungi are capable of degrading the fish scale component.
\end{abstract}

Keywords: Biodegradation; fish scale; fungi; mangrove

\section{INTRODUCTION}

Mangroves are salt tolerant inter-tidal wetland ecosystem found mainly in the tropical and subtropical inter-tidal zones largely confined to the region between $30^{\circ}$ north and the south of the equator [1]. Approximately, $25 \%$ of the World's coastline is dominated by mangroves distributed in 114 countries and territories encompassing an area of 15 million ha world-wide. Sundarbans, the world's largest coastal wetland comprising of highly dense mangrove forest along with numerous flora and fauna, covers about 1 million ha in the delta of the rivers Ganga, Brahmaputra and Meghna [2]. The muddy and sandy soils in mangrove communities with loose sediment and submerged mangrove roots, trunks and branches easily attract rich communities of fungi [3]. Moreover, Mangroves being detritus based ecosystems, substantial fungal populations are involved in detritus processing. Studies revealed that mangrove fungi are the second largest group among the marine fungi [4]. The present pattern of assessment of higher fungi in the mangrove ecosystem is biased towards assessment of typical mangrove fungi and the rest (e.g. terrestrial fungi) are ignored. Mangrove fungi have 
morphologically and physiologically adapted to habitats with high salinity, tidal inundation, high wind velocity, high temperature and anaerobic clayey soils, therefore it differs from other terrestrial fungi [5]. Fungi have multi-directional applications in different industries like food, dairy, textile, Effluent treatment, pharmaceutical and pulp and paper industries [6]. Studies revealed that mangrove fungi are magnificent in production of xylanase in enzymatic pre-treatment of recycled paper pulps [7] and also beneficial on conservation of biodiversity of different coastal areas of India [8,9]. Therefore it might be having role it solid waste management system. Fish scale is a chief waste material from fish processing industries. It is dermally derived, specifically in the mesoderm, bio composites of highly ordered type I collagen fibres and hydroxyapatite $\mathrm{Ca}_{10}(\mathrm{OH})_{2}\left(\mathrm{PO}_{4}\right)_{6}[10]$. Annually over 100 million tons of fish are harvested worldwide, and about half of the total catch is discarded as processing waste [11]. Biodegradation of these huge waste using fungi can be a very valuable waste management practice. Furthermore, this degradation mechanism may also produce some industrially significant component or polymer. Thus, this primary study will serve three clear purposes: firstly to find out the bioprospects of mangrove fungi, secondly to frame a fish scale management practice and thirdly to establish the platform for investigating the potentiality of green synthesis of some polymers from fish scale in future. This proposed study will focus on the potentiality assessment of fish scale biodegradation using mangrove fungi isolated from Indian Sundarban.

\section{MATERIALS AND METHODS}

\section{1. Sample collection and sample location site}

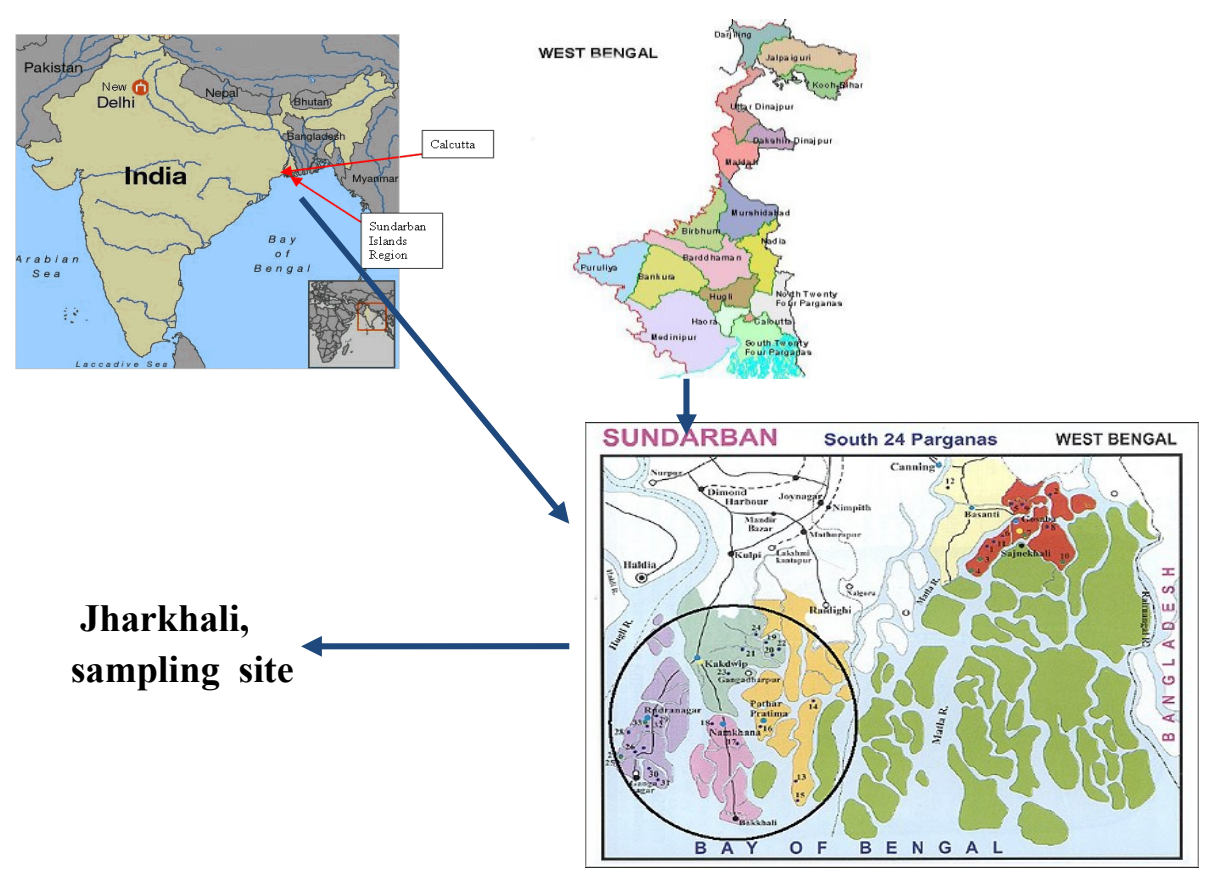

Figure 1. Sample location site, Jharkhali, Sundarban, India. Reference: https://www.google.co.in/sundarban map.

Soil sample were collected using sterile tools from, Jharkhali, Sundarban, $\left(22^{\circ} 1^{\text {, }}\right.$ $18.80^{\prime} \mathrm{N} 88^{\circ} 41^{\prime} 07.06^{\prime}$ E) [Fig. 1], West Bengal, India. This is a habitat of a number of true 
mangrove species like Avicennia marina, Avicennia albe, Exocoecaria agallocha, Rhizophora mucronata, Sonneratia caseolaris etc. The samples were stored in an aseptic condition until reached to the laboratory.

\section{2. Chemicals and reagents}

The analytical grade chemicals, reagents and media components used in this study were purchased from Merck, India and HiMedia, India.

\section{3. Physicochemical characterization of soil samples}

Physico-chemical parameters such as temperature, colour, $\mathrm{pH}$, moisture content, organic carbon, nitrogen were measured to get an idea of the habitat of fungi to be isolated. Temperature and colour of the soil samples was recorded on the spot. Moisture content, $\mathrm{pH}$ and $\%$ organic Carbon, $\%$ organic nitrogen was measured according to Standard procedure as given below.

\section{3. 1. Moisture content}

$10 \mathrm{~g}$ of soil samples were dried at $60^{\circ} \mathrm{C}$ for $72 \mathrm{~h}$ in Hot Air Oven and then the moisture content was calculated [12]. Dry weight of the sample was taken till it showed its constant weight. The percent moisture was expressed as follows:

Moisture $\%=(\mathrm{W} 1-\mathrm{W} 2) / 100 \times 100$

where, $\mathrm{W} 1=$ Weight of soil before oven drying

$\mathrm{W} 2=$ Weight of soil after oven drying

\section{3. 2. pH of soil sample}

Soil sample were dried at $50{ }^{\circ} \mathrm{C}$ for 72 hours, powdered in pestle and mortar and filtered through $2 \mathrm{~mm}$ sieve and the sieved soil were dissolved in distilled water $(2.5 \mathrm{w} / \mathrm{v})$ and vortexing for 5 minutes at $120 \mathrm{rpm}$ then $\mathrm{pH}$ was measured by digital $\mathrm{pH}$ meter [13].

\section{3. 3. Percent organic Carbon / Nitrogen}

$1 \mathrm{~g}$ soil sample was mixed with $10 \mathrm{ml}$ potassium dichromate $(1 \mathrm{~N})$ and $20 \mathrm{ml}$ concentrated $\mathrm{H}_{2} \mathrm{SO}_{4}$. Then $150 \mathrm{ml}$ distilled water and $25 \mathrm{ml} \mathrm{FeSO}_{4}(0.5 \mathrm{M})$ were added and the excess was titrated against potassium permanganate $(0.1 \mathrm{~N})$ solution to pink end point $[14,15]$.

$\%$ Organic carbon $=(\mathrm{A}-\mathrm{B}) / \mathrm{C} \times 0.3 \times 1.33$

where;
A. Volume of $\mathrm{K}_{2} \mathrm{Cr}_{2} \mathrm{O}_{7} \times$ Normality of $\mathrm{K}_{2} \mathrm{Cr}_{2} \mathrm{O}_{7}$,
B. Volume of $\mathrm{KMnO}_{4} \times$ Normality of $\mathrm{KMnO}_{4}$,
C. Weight of sample: Soil organic nitrogen was calculated using following equation
Organic nitrogen $(\%)=0.862 \times \%$ organic carbon 


\section{4. Isolation of mangrove fungi from the soil sample}

\section{4. 1. Soil dilution plate method}

$1 \mathrm{~g}$ of soil sample was suspended in $10 \mathrm{ml}$ of sterile distilled water to make microbial suspensions $\left(10^{-1}\right.$ to $\left.10^{-5}\right)$. Dilution of $10^{-3}, 10^{-4}$ and $10^{-5}$ were used to isolate fungi. $0.1 \mathrm{ml}$ of microbial suspension of each concentration were added (pour plate technique) to sterile Petri dishes (triplicate of each dilution) containing $15 \mathrm{ml}$ of sterile Potato Dextrose Agar (Peeled Potato $200.0 \mathrm{~g}$, Dextrose $20.0 \mathrm{~g}$ ) [16]. $1 \%$ Ampicillin solution was added to the medium before pouring into Petri dishes for preventing bacterial growth. The Petri dishes were then incubated at $28 \pm 2{ }^{\circ} \mathrm{C}$ in dark. The plates were observed everyday up to four days.

\section{4. 2. Identification of the soil fungi}

Fungal morphology were studied macroscopically by observing colony features (Colour and Texture) and microscopically by staining with lacto phenol cotton blue and observe under compound microscope for the conidia, conidiophores and arrangement of spores [17]. The fungi were identified with the help of literature $[18,19]$.

\section{5. Processing of fish scale}

In the present study, fish scales of catla catla were collected from market and washed with deionised water, dried in mechanical drier for $12 \mathrm{~h}$ at $100{ }^{\circ} \mathrm{C}$. Then scales were crushed to almost powdered form. Crushed scale $(2.5 \%)$ was used in media preparation for degradation study [20].

\section{6. Preparation of media for degradation study}

Potato dextrose agar was prepared with $2.5 \%$ fish scale powder. $1 \%$ Ampicillin solution was added for preventing bacterial growth. Sterile media was poured into Petri dishes under aseptic condition [20]. Isolated fungi cultures were inoculated into potato dextrose agar plates with fish scale powder. The Petri dishes were then incubated at $28 \pm 2{ }^{\circ} \mathrm{C}$ in dark. The plates were observed every day to monitor the zone of clearance if any up to four days.

\section{RESULTS AND DISCUSSION}

\section{1. Characterization of physiochemical parameters of soil samples}

The physiochemical properties of soil [Table 1] used for isolation of microbial species were analyzed in the present study. The colour of soil samples was brown to black, with variation in $\mathrm{pH} 6.28 \pm 0.2$. The temperature of the soil was high $\left(28-30{ }^{\circ} \mathrm{C}\right)$ with great variation in percent moisture content $31.194 \%$, organic carbon $0.12 \%$ and percent organic nitrogen $0.0392 \%$. Soil properties like organic matter, $\mathrm{pH}$ and moisture content etc., affects the density and diversity of microbes in the soil. Therefore, it is important to study the relation between soil physicochemical properties and abundance of indigenous microorganisms. A certain minimum level of organic matter and moisture content is essential to ensure the presence of an active microbial population in the soil. In the present study, the important physicochemical properties of the soils, used for the evaluation of natural fungal density, were determined. 
Table 1. Physico-chemical properties of soil.

\begin{tabular}{|c|c|c|}
\hline Sl. No & Physicochemical Properties of soil & Result \\
\hline 1. & Colour of soil & Brown to Black \\
\hline 2. & Temperature & $28-30{ }^{\circ} \mathrm{C}$ \\
\hline 3. & $\mathrm{pH}$ & $6.28 \pm 0.2$ \\
\hline 4. & Moisture content & $31.194 \%$ \\
\hline 5. & Carbon content & $0.12 \%$ \\
\hline 6. & Nitrogen content & $0.0392 \%$. \\
\hline
\end{tabular}

\section{2. Isolation and characterization of fungal strains}

A total of 6 fungal isolates were obtained from the analysis of soil samples taken from pesticide contaminated soils through soil dilution agar plating method. All fungal isolates were obtained in pure cultures by using standard techniques. The photographs of all the fungal isolates were taken helps in identification of the fungal isolates. The cultural characteristics of these isolates are presented in [Figure $2 \&$ Table 2].

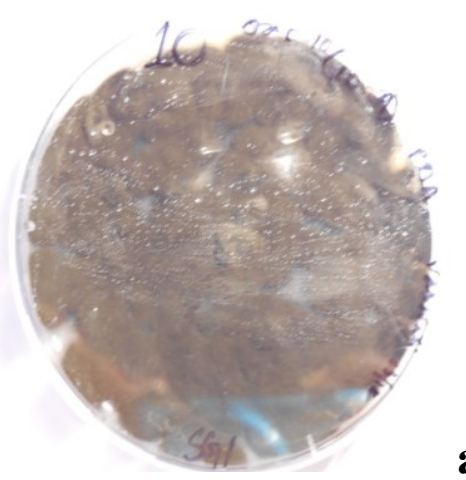

$\mathbf{a}$

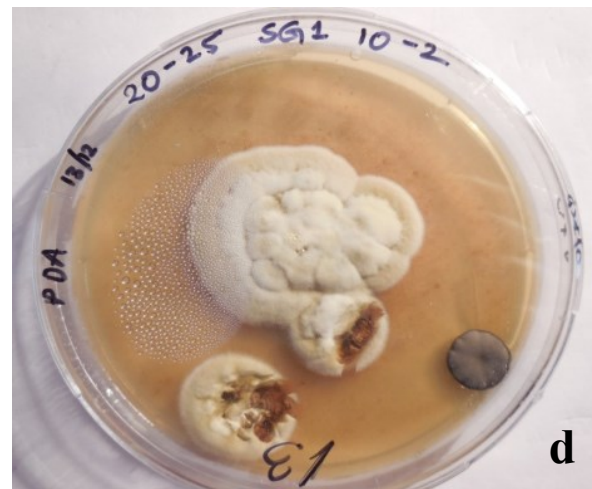

b
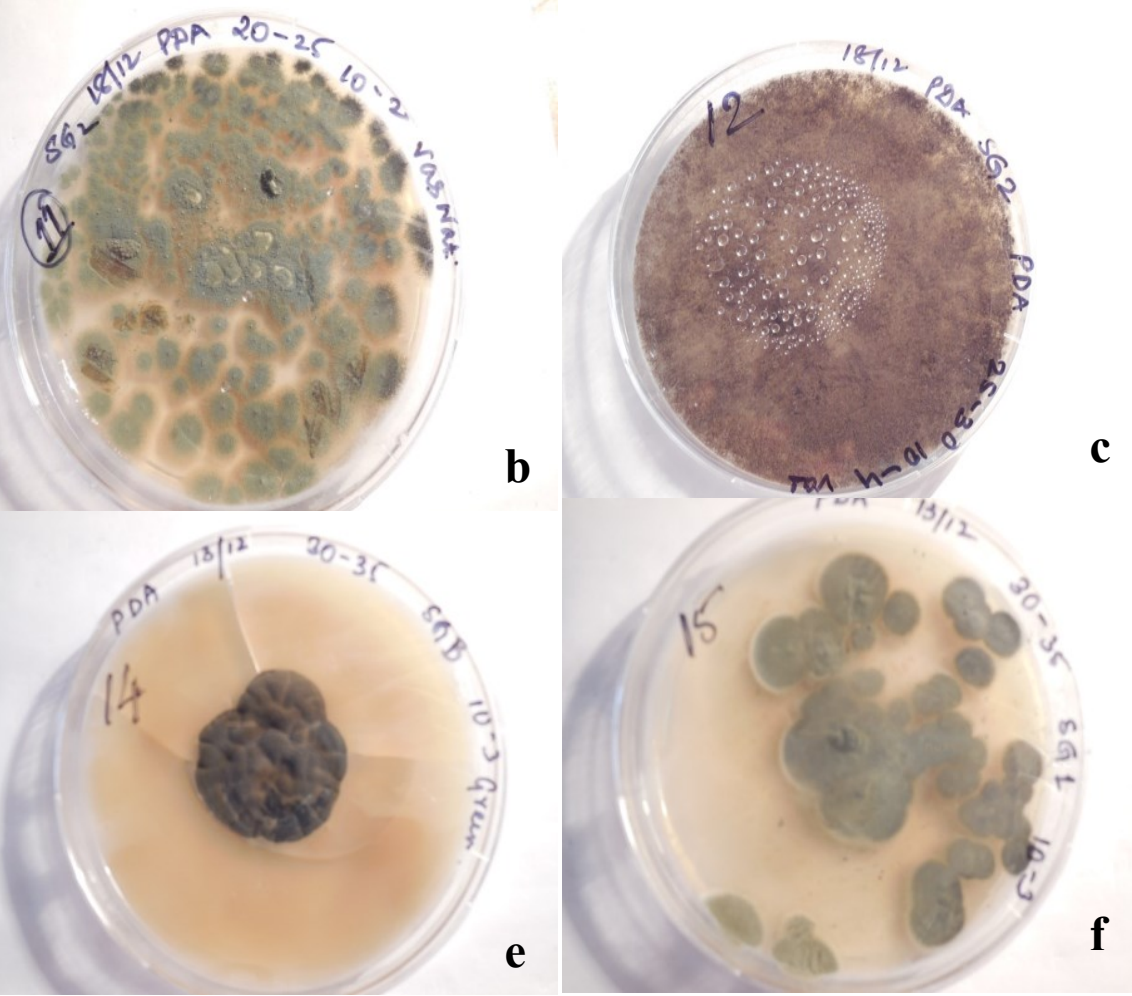

Figure 2. Cultural characteristics of fungal isolates. 
Table 2. Cultural characteristics of fungal isolates.

\begin{tabular}{|c|c|c|}
\hline Sl. No. & Colour of the colony & Morphological characteristics \\
\hline 1. & Dark brown to black & Dusty sporulated round colonies. \\
\hline 2. & Bottle green & Round colonies, wooly, sporulated. \\
\hline 3. & Dark brown & Cottony colony less sporulated \\
\hline 4. & Off white & $\begin{array}{c}\text { Roughly round, Velvety, convex, uneven margin } \\
\text { with no sporulation }\end{array}$ \\
\hline 5. & Blackish green & Velvety roughly round shining colony with no spore \\
\hline 6. & Green & Small round with proper margin, no sporulation. \\
\hline
\end{tabular}

The isolates from mangrove soils were identified as filamentous fungi. These isolates were identified to the species level. Two of them were found to be Aspergillus niger and Penicillium $s p$. Rests of the strains were not identified owing to the lack of sporulating structures under presently used incubation conditions. Such strains were designated as Mycelia sterilia.

In such soil fungi may occur either as resting propagules or as active mycelia depending on the availability of nutrients and favourable environmental conditions [12]. Aspergillus niger [Figure 3] has been reported as an important strain helps in production protein rich organic fertilizer from fish scale [10].

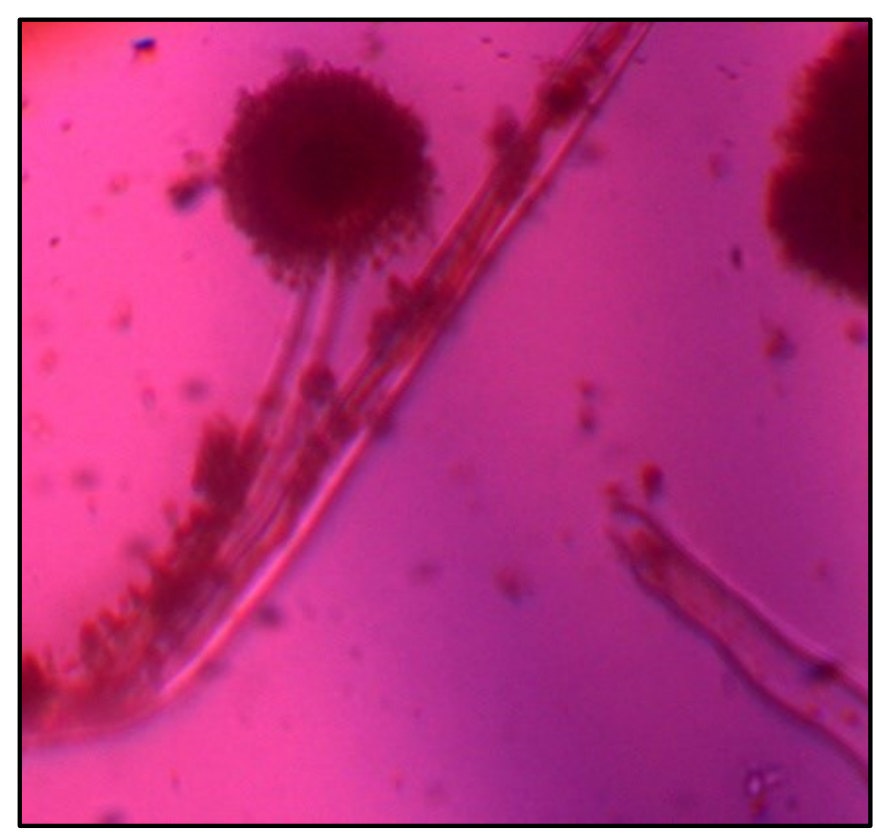

Figure 3. Microscopic image of Aspergillus niger (200x). 


\section{3. Degradation of fish scale by fungal isolates}

The study reveals that the isolated mangrove fungi have potentiality to degrade complex organic molecule like fish scale powder to simple molecule. Here, the potato dextrose agar plate supplemented with fish scale powder inoculated with test organism has shown the degradation by showing zone of clearance. The test organism was also grown on normal potato dextrose agar plate indicated as control where no fish scale supplement was added. No zone of clearance was observed in the control plate which indicates that the fungi were only degrading the fish scale component not the media component [Figure 4a]. Aspergillus niger was found to be the best for the degradation of fish scale by producing zone of clearance shown in Figure $4 b$ and $4 c$.

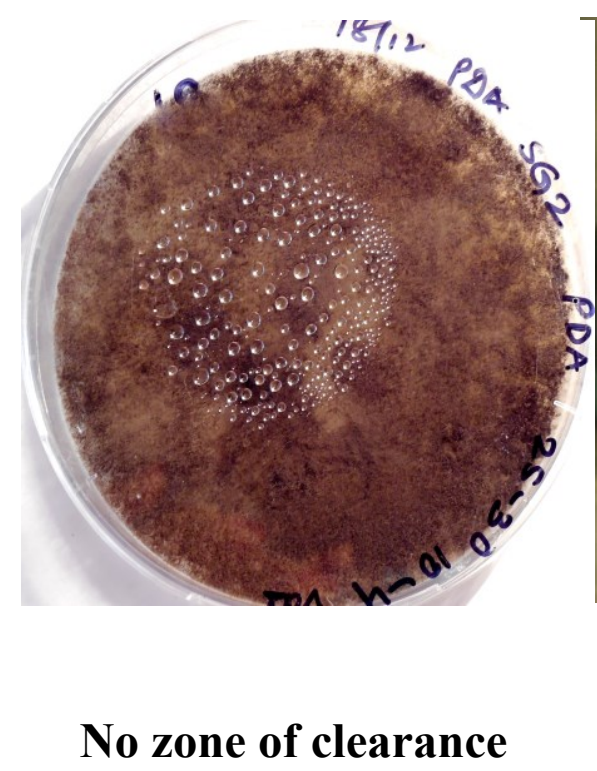

(a)

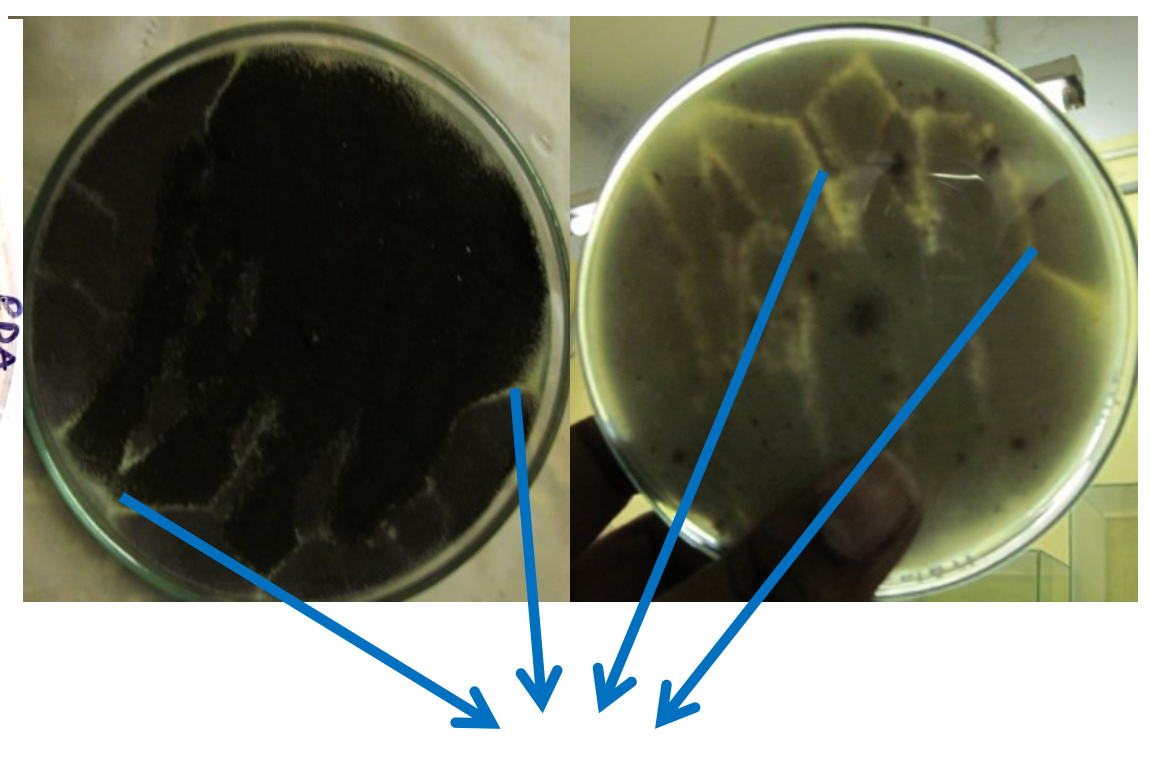

Zone of clearance

(b)

(c)

Figure 4. Plate of Aspergillus niger grown on potato dextrose agar plate as control [a]; Degradation of fish scale powder by Aspergillus niger; zone of clearance front view [b];

Zone of clearance back view [c].

\section{CONCLUSIONS}

In the present study, total six fungi isolated from Jharkhali soil sample were studied for the assessment of their potentiality of biodegradation pattern of fish scale. The result obtained from the study clearly idicates that Aspergillus niger to be the best strain to break down fish scale by producing zone of clearance by utilizing the component of scale. There are many researches on chemical mediated degradation, but biodegradation of scale using fungi is very rare. Here, the bio degradation of fish scale by mangrove fungi is a primary qualitative study. Further studies are being carried out to quantify the fish scale reduction by investigating the percentage of whole scale weight reduction in the biodegradation process. In this study, the bioprospects of mangrove fungi is found to be quite interesting, having the potentiality to degrade fish scale by utilizing it as their nutritional supplement. 
This bio degradation process is beneficial to waste management procedure of a worldwide market waste, fish scale. The primary biodegradation study gives rise to further research problem regarding a green synthesis of industrially significant some polymeric components from fish scale. Additionally, the biodegradation process can be co-related with the physico-chemical properties of the soil from where the fungi was isolated so that the same process with different soil samples implies a comparative analysis of the parameters and figure out the parameters which may affect the degradation pattern.

\section{ACKNOWLEDGEMENT}

The authors are thankful to Department of Science and Technology (DST), India, Google, USA, Department of Environmental Science, University of Calcutta, India for the financial and infrastructural support.

\section{References}

[1] FAO. Mangrove Guidebook for South East Asia (2007).

[2] M. Radhakrishnan, D. Saravanan, International Journal of Pharma Tech Research 3(2) (2011) 719-723.

[3] K. Vanmathi S. et al, International Journals of Current Microbiology and Applied Sciences 2(1) (2013) 33-49.

[4] R. Latha, Sudip Mitra, Journal of Biotechnology (1998)13-26.

[5] Seth P. K., A. K., Bull. Environmental Contamination Toxicology 43 (1989) 28-35.

[6] Krishnamurthy K, Choudhury A., Untawale A. G., Status report-Mangroves in India. Ministry of Environmentand Forests, Government of India, New Delhi, 1987.

[7] Lars H. et al., Association of manufactures and formulators of enzyme products (2009) 269-273.

[8] Torres J. M., Dela Cruz T. E., World journal Microbiology and Biotechnology 29(4) (2013) 645-55.

[9] V. Venkateswara Sharma, B. P. R Vittal, Journal of Fungal Biodiversity (2000) 23-41.

[10] R. Saravanan, T. Sivakumar, International Journals of Current Microbiology and Applied Sciences 2(7) (2013) 192-201.

[11] Fengxiang Zhang, Anning Wang, Zhihua Li, Shengwen He, Lijun Shao. Food and Nutrition Sciences 2 (2011) 818-823.

[12] You J. J., Hee G. B., Se K K., Process biochemistry 35 (2000) 471-478.

[13] Jackson M. L., Prentice Hall of India, Pvt. Ltd., New Delhi, 1967, 498.

[14] Walkley A., and Black I.A, Soil Sci., 63, (1934) 251-263.

[15] Moodie C. D., Smith H. W., McCreery R. A., Laboratory Manual for Soil Fertility, Washington State College, Mimeograph, USA (1959).

[16] Waksman S. A., Journals of Bacteriology 7 (1922) 339-341. 
[17] Aneja K. R., Experiments in Microbiology, Pant pathology and Biotechnology, New age International Publishers 4 (2001) 157-162.

[18] J. C. Gilman, A Manual of Soil fungi, 2nd Indian edition, Biotechnology Books, Delhi, (2001) 256-262.

[19] A. Nagamani, I. K. Kunwar, Hand book of soil fungi, I. K. International Pvt. Ltd; (2006) 88-93.

[20] Barnali Basu, Ajit K. Banik, Journal of scientific and industrial research 64 (2005) 293-298. 